\title{
ECLETICA
}

www.scielo.br/eq

www.ecletica.iq.unesp.br

Volume 32, número 3, 2007

\section{A study on the inhibition of mild steel corrosion in hydrochloric acid by pyridoxol hydrochloride.}

\author{
A.O.James ${ }^{1}$, * N.C. Oforka ${ }^{1}$, O.K. Abiola ${ }^{1}$ and B.I.Ita ${ }^{2}$. \\ 1. Department of Pure and Industrial Chemistry, University of Port Harcourt, P.M.B. 5323, \\ Port Harcourt, Nigeria. \\ 2. Department of Pure and Applied Chemistry, University of Calabar, Calabar, Nigeria.
}

\begin{abstract}
The inhibition of the corrosion of mild steel in 2M hydrochloric acid solutions by Pyridoxol hydrochloride (PXO) has been studied using weight loss and hydrogen evolution techniques. The inhibitor (PXO) exhibited highest inhibition efficiency of $71.93 \%$ at the highest inhibitor concentration of $1.0 \times 10^{-2} \mathrm{M}$ investigated and a temperature of 303K from weight loss result. Also, inhibition was found to increase with increasing concentration of the inhibitor and decreasing temperature. A first order type of mechanism has been deduced from the kinetic treatment of the weight loss results and the process of inhibition attributed to physical adsorption. The results obtained from the two techniques show that pyridoxol hydrochloride could serve as an effective inhibitor of the corrosion of mild steel in $\mathrm{HCl}$ acid solution. The compound obeys the Langmuir adsorption isotherm equation.
\end{abstract}

Keywords: corrosion; mild steel; pyridoxol hydrochloride; kinetic treatment.

\section{Introduction}

The continued manifestation of corrosion and corrosion products on steel structures is still causing a lot of concern to corrosion scientists and engineers [1-2]. In recent years, scientists have been concerned with the use of certain organic compounds as corrosion inhibitors in metalcorrodent system. The use of nitrogen $(\mathrm{N})$ and sulphur (S) containing organic compounds for the corrosion of mild steel in hydrochloric acid solutions has been reported by several authors [3-7]. Of interest to corrosion scientists is the effect of molecular structural changes on corrosion inhibition which is being investigated in our laboratory.

In continuation of the search for efficient eco-friendly corrosion inhibitors for mild steel in hydrochloric acid, this paper reports the inhibition effects of pyridoxol hydrochloride on mild steel corrosion in hydrochloric acid. This study is a continuation of our extensive studies on the efficiency of Pyridoxol hydrochloride (PXO) as potential corrosion inhibitor for aluminum alloy of type aluminum 3SR in hydrochloric acid [8].

The inhibition efficiency, (\%E) was calculated from the equation (1) below:

$$
\% \mathrm{E}=\frac{\Delta W_{B}-\Delta W_{i}}{\Delta W_{B}} \times \frac{100}{1}
$$

Where $\Delta W_{B}$ and $\Delta \mathrm{W}_{\mathrm{i}}$ are the weight loss (or hydrogen gas evolution) data of metal coupons in the absence and presence of the inhibitors respectively.

\section{Experimental details \\ Material preparation}

The sheet of mild steel obtained from System Metals Industries Ltd., Calabar, Nigeria and of thickness $0.07 \mathrm{~cm}$, purity 98.774\% Fe had the chemical composition 
of $\mathrm{C}=0.12 \%, \mathrm{Mn}=0.90 \%, \mathrm{~S}=0.066 \%$, $\mathrm{P}=0.050 \%, \mathrm{Si}=0.10 \%$ and remainder $\mathrm{Fe}$. The mild steel sheet was mechanically press-cut into 5 X $2 \mathrm{~cm}$ coupons. Each coupon was perforated with a hole of the same of about 0.02 in diameter at one end to allow the passage of a glass hook.

The coupons were used as supplied without further polishing. However, they were degreased in absolute ethanol, rinsed with double-distilled water and dried in acetone. This process enabled mill scales to be removed from the coupons. The treated coupons were then stored over calcium chloride in moisture free desiccators to prevent contamination before their use for corrosion studies.

The Pyridoxol hydrochloride used as inhibitor was obtained from BDH, England.

\section{Weight loss determination}

The weight loss was determined following the method reported earlier [8]. Three sets of experiments were carried out consisting of fifteen $250 \mathrm{ml}$ beakers, which separately contained 1.0M, 2.0M, 3.0M, 4.0M and 5.0M HCl solutions, maintained at $303 \mathrm{~K}, 313 \mathrm{~K}$ and $323 \mathrm{~K}$. Previously weighed mild steel coupons were each suspended in each beaker with the help of glass rods and glass hooks.

The mild steel coupons were retrieved from the corrodent solutions at 24hours interval progressively for 192hours (8days).

Each retrieved coupon was immersed in a solution of $20 \%$ sodium hydroxide containing $200 \mathrm{~g}$ / liter of Zn dust, scrubbed with brittle brush several times to remove corrosion product, dried in acetone and then reweighed. The weight loss was calculated in grams as the difference between the initial weight prior to immersion, and weight after removal of the corrosion product.

Each reading reported is an average of three readings recorded to the nearest 0.0001g on a Mettler AE 166 Delta range analytical balance.
Experiments were repeated with the introduction of five different concentrations $\left(1.0 \times 10^{-2} \mathrm{M}, 1.0 \times 10^{-3} \mathrm{M}, 1.0 \times 10^{-4} \mathrm{M}, 1.0\right.$ $\mathrm{x} 10^{-5} \mathrm{M}$ and $1.0 \times 10^{-6} \mathrm{M}$ ) of the inhibitor pyridoxol hydrochloride ( $\mathrm{PXO}$ ) in $2 \mathrm{M} \mathrm{HCl}$ solutions at $303 \mathrm{~K}, 313 \mathrm{~K}$ and $323 \mathrm{~K}$ in fifteen $250 \mathrm{ml}$ beakers. Previously weighed coupons were then placed in the test solutions with each test solution containing one mild steel coupon. As before, each coupon was retrieved from the test solutions at 24hours intervals progressively for 192hours (8 days) washed and reweighed. The difference in weight of the coupons was again taken as the weight loss in grams.

Hydrogen evolution determination, via the gasometric assembly

The gasometric assembly used for the measurement of hydrogen gas evolution from the corrosion reaction was designed following the method described by Onuchukwu [9]. The gasometric assembly measures the volume of hydrogen gas evolution from the reaction system. Six mild steel coupons of dimension $5 \mathrm{~cm} \times 2 \mathrm{~cm}$ $\mathrm{x} 0.07 \mathrm{~cm}$ were used in the experiments for test solutions containing $8 \mathrm{M} \mathrm{HCl}$ with the five different concentrations of PXO and the blank at $303 \mathrm{~K}$. A $50 \mathrm{ml}$ of each test solution was introduced into the reaction vessel connected to a burette through a delivery tube. The initial volume of air in the burette was recorded. Thereafter, one mild steel coupon was dropped into the corrodent and the reaction vessel quickly closed. Variation in the volume of hydrogen gas evolved with time was recorded every $1 \mathrm{~min}$. for $60 \mathrm{~min}$. Each experiment was conducted on a fresh specimen of metal coupon. The hydrogen gas evolved displaced the paraffin oil in the gasometric set-up and the displacement representing the volume of hydrogen evolved was read directly.

The experiment was repeated in the presence of the five different concentrations 
of PXO, $1.0 \times 10^{-2} \mathrm{M}$ to $1.0 \times 10^{-6} \mathrm{M}$ as used in the weight loss experiments.

\section{Results and discussion}

\section{Effect of corrodent concentration}

Fig. 1 shows that mild steel corrodes in different concentrations of $\mathrm{HCl}$ solutions, since there was a decrease in the original weight of mild steel. The corrosion is attributed to the presence of water, air and $\mathrm{H}^{+}$, which accelerate the corrosion process. The corrosion of the mild steel in $\mathrm{HCl}$ increases with the concentration of the acid and time. Similar results were obtained at $313 \mathrm{~K}$ and $323 \mathrm{~K}$. This observation is attributed to the fact that the rate of chemical reaction increases with increasing concentration.

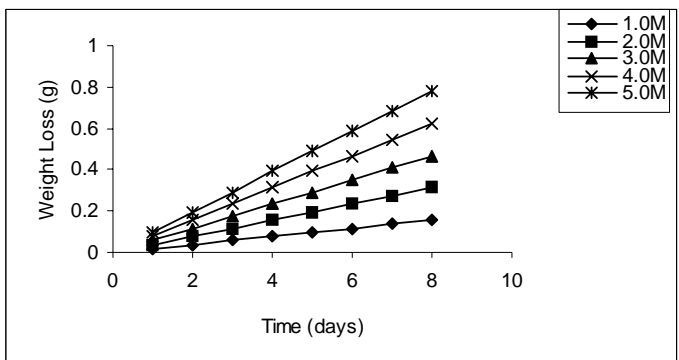

Fig. 1: - Variation of weight loss (grams) of mild steel with time (days) for different concentrations of $\mathrm{HCl}$ solution at $303 \mathrm{~K}$.

\section{Effect of temperature on the corrosion of mild steel}

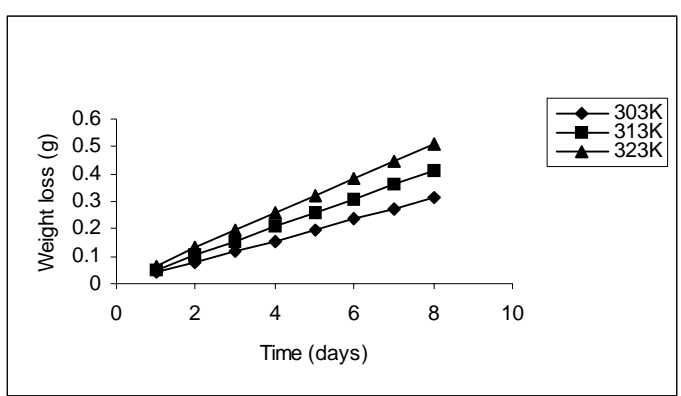

Fig. 2: Variation of weight loss (g) with time (days) for mild steel coupons in $2 \mathrm{M} \mathrm{HCl}$ solutions at different temperatures without inhibitor
There is a progressive increase in weight loss as the temperature is increased from 303K to 323K (fig. 2). This signifies that the dissolution of the metals increased at higher temperatures. This observation is attributed to the general rule guiding the rate of chemical reaction, which says that chemical reaction increases with increasing temperatures. Also an increased temperature favors the formation of activated molecules, which may be doubled in number, with $10^{\circ} \mathrm{C}$ rise in temperature, thereby increasing the reaction rate. This is because the reactant molecules gain more energy and are able to overcome the energy barrier more rapidly [7]. An increase in temperature may also increase the solubility of the protective films on the metals, thus increasing the susceptibility of the metal to corrosion [10]. The solubility of oxygen gas decreases with increase in temperature. Thus oxygen concentration is expected to be more at higher temperature which in this case is higher at $323 \mathrm{~K}$ than at 313 and $303 \mathrm{~K}$. The presence of high concentration of oxygen thereby causes the metal to corrode faster. Also for solids, solubility generally increases with increasing temperature. This explains why the protective film which is solid becomes more soluble as the temperature is increased.

Inhibition action of pyridoxol hydrochloride on the corrosion of mild steel

Fig. 3 shows that $\mathrm{PXO}$ is indeed a corrosion inhibitor, since there was a general decrease in weight loss at the end of the corrosionmonitoring process. Similar trend was observed at 313K and 323K. The general decrease in hydrogen gas evolution with time as concentration of additives increased from $0.00001 \mathrm{M}$ to $0.01 \mathrm{M}$ (fig. 4) confirms that the presence of the additives in $8 \mathrm{M}$ $\mathrm{HCl}$ solution also reduced the corrosion of mild steel. It must be mentioned that the hydrogen evolution technique enables us to assess the inhibitory effect of the inhibitor at very high corrodent concentrations up 
to $8 \mathrm{M} \mathrm{HCl}$ which could not be done with the weight loss technique. The mild steel coupons disappeared in $8 \mathrm{M} \mathrm{HCl}$ within 5hours of immersion thereby making it difficult to use the weight loss technique for the 24hours studies.

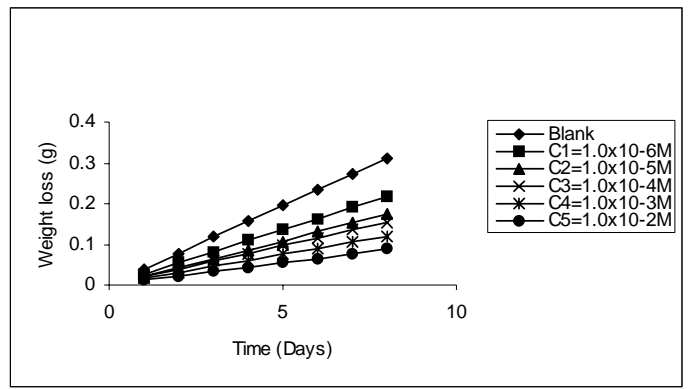

Fig. 3: Variation of weight loss (g) with time (days) for mild steel coupons in $2 \mathrm{M} \mathrm{HCl}$ solution containing different concentrations (ci's) of pyridoxol hydrochloride at 303K.

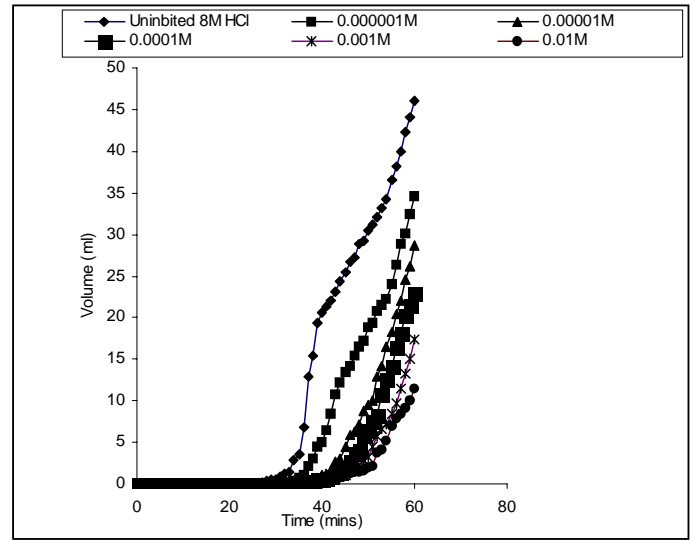

Fig. 4: Variation of Volume of Hydrogen gas evolved with time (minutes) for the inhibition of mild steel in 8M HCl solutions by Pyridoxol Hydrochloride at $303 \mathrm{~K}$
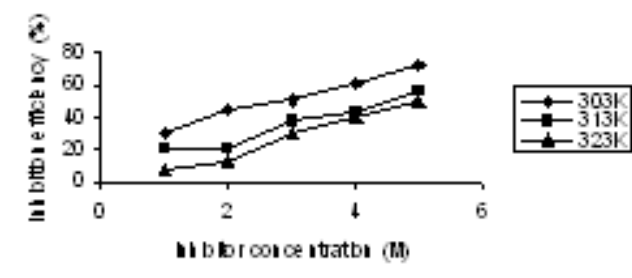

Fig. 5: Variation of inhibition efficiency (\%) with inhibitor concentrations (M) for mild steel coupons in $2 \mathrm{M} \mathrm{HCl}$ solution containing pyridoxol hydrochloride at different temperatures.
Kinetics and mechanism of the corrosion inhibition of mild steel in HCl by pyridoxol hydrochloride.

The corrosion of mild steel in $\mathrm{HCl}$ solution is a heterogeneous one, composed of anodic and cathodic reactions. Based on this, kinetic analysis of the data is considered necessary.

In the present study, the original weight of mild steel coupon at time, $\mathrm{t}$ is designated $\mathrm{Wi}$, the weight loss is $\Delta \mathrm{W}$ and the weight change at time $\mathrm{t}$, (Wi - $\Delta \mathrm{W})$. The plots of a linear $\log (\mathrm{Wi}-\Delta \mathrm{W})$ against time (days) at $303 \mathrm{~K}$ and other temperatures studied, showed variation which confirmed a first order reaction kinetics with respect to the corrosion of mild steel in $\mathrm{HCl}$ solutions at $303 \mathrm{~K}$ without inhibitor (fig. 6).

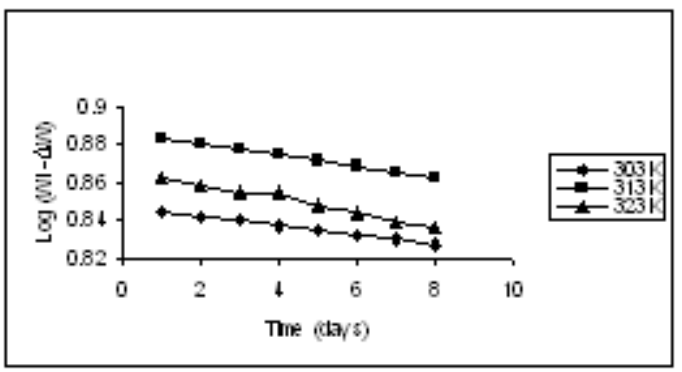

Figure 6: Variation of Log $(\mathrm{Wi}-\Delta \mathrm{W})$ with time (days) for mild steel coupons in $2 \mathrm{M} \mathrm{HCl}$ solution at different temperatures without inhibitor.

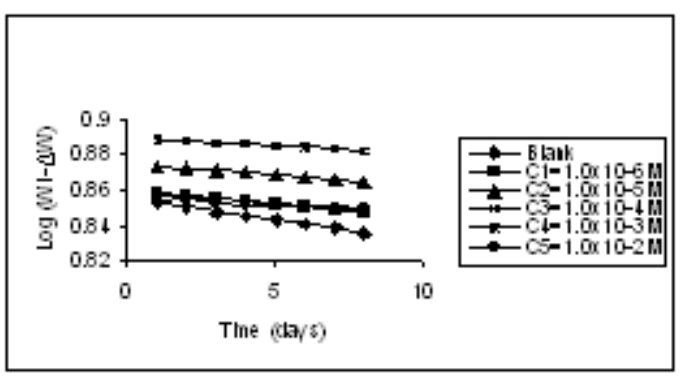

Figure 7: Variation of Log $(\mathrm{Wi}-\Delta \mathrm{W})$ with time (days) for mild steel coupons in $2 \mathrm{M} \mathrm{HCl}$ solutions containing different concentration of pyridoxol hydrochloride at $303 \mathrm{~K}$. 
TABLE 1: The kinetic data for Mild steel in different concentrations of hydrochloric acid solutions without additives (Inhibitor).

\begin{tabular}{|l|l|l|l|l|l|l|l|l|}
\hline $\begin{array}{l}\text { Hydrochl } \\
\text { oride } \\
\text { acid } \\
\text { concentra } \\
\text { tion (M) }\end{array}$ & $\begin{array}{l}\text { Rate Constant, K (day-1) X } \\
10^{-3}\end{array}$ & \multicolumn{2}{l}{ Half-Life, $\mathrm{t}_{1 / 2}$ (days) X $10^{2}$} & $\begin{array}{l}\text { Activatio } \\
\mathrm{n} \text { Energy } \\
\mathrm{kJmo}^{-1}\end{array}$ & $\begin{array}{l}\text { Average } \\
\text { Activatio } \\
\mathrm{n} \text { Energy } \\
\mathrm{kJmo}^{-1}\end{array}$ \\
\hline & $303 \mathrm{~K}$ & $313 \mathrm{~K}$ & $323 \mathrm{~K}$ & $303 \mathrm{~K}$ & $323 \mathrm{~K}$ & $323 \mathrm{~K}$ & & \\
\hline 1.0 & 2.69 & 3.53 & 4.48 & 2.58 & 1.96 & 1.55 & 21.43 & \\
\hline 2.0 & 5.63 & 6.81 & 8.88 & 1.23 & 1.02 & 0.78 & 15.01 & \\
\hline 3.0 & 7.90 & 10.42 & 12.94 & 0.88 & 0.67 & 0.54 & 21.83 & 20.15 \\
\hline 4.0 & 10.83 & 14.19 & 19.35 & 0.64 & 0.49 & 0.36 & 21.31 & \\
\hline 5.0 & 13.33 & 17.43 & 22.05 & 0.52 & 0.40 & 0.31 & 21.15 & \\
\hline
\end{tabular}

TABLE 2: The kinetic data for Mild steel in $2 \mathrm{M} \mathrm{HCl}$ solution containing Pyridoxol hydrochloride at different temperatures.

\begin{tabular}{|c|c|c|c|c|c|c|c|c|c|c|}
\hline \multirow[t]{2}{*}{$\begin{array}{l}\text { Inhibitor } \\
\text { Concentr } \\
\text { ation (M) }\end{array}$} & \multicolumn{3}{|c|}{$\begin{array}{l}\text { Rate Constant, K } \\
\left(\text { day }^{-1}\right) \times 10^{-3}\end{array}$} & \multicolumn{3}{|c|}{ Half-Life, $\mathrm{t}_{1 / 2}$ (days) $\times 10^{2}$} & \multicolumn{2}{|c|}{$\begin{array}{l}\text { Activation Energy } \\
\text { KJmo1 }^{-1}\end{array}$} & \multicolumn{2}{|c|}{$\begin{array}{l}\text { Average Activation } \\
\text { Energy } \mathrm{KJmo}^{-1}\end{array}$} \\
\hline & $303 K$ & $313 \mathrm{~K}$ & $323 K$ & $303 K$ & $313 \mathrm{~K}$ & $323 K$ & \begin{tabular}{|l}
$303 K$ \\
$313 K$
\end{tabular} & 313K-323K & 303K-313K & 313K-323K \\
\hline $1.0 \times 10^{-6}$ & 3.78 & 6.09 & 8.41 & 1.83 & 1.14 & 0.82 & 37.61 & 27.15 & & \\
\hline $1.0 \times 10^{-5}$ & 2.91 & 5.81 & 7.83 & 2.38 & 1.19 & 0.89 & 54.53 & 25.08 & & \\
\hline $1.0 \times 10^{-4}$ & 2.67 & 4.44 & 5.85 & 2.60 & 1.56 & 1.18 & 40.11 & 23.19 & 50.04 & 23.89 \\
\hline $1.0 \times 10^{-3}$ & 1.96 & 4.17 & 5.24 & 3.54 & 1.66 & 1.32 & 59.54 & 19.20 & & \\
\hline $1.0 \times 10^{-2}$ & 1.54 & 3.23 & 4.34 & 4.50 & 2.15 & 1.60 & 58.41 & 24.83 & & \\
\hline
\end{tabular}

There is a general decrease in the rate constants from $303 \mathrm{~K}$ - 323K with increasing concentrations of the additives (Tab. 2). The increase in half-life $\left(\mathrm{t}_{1 / 2--}\right)$ (half-life being the time taken for the concentration of a substance to reduce to half its initial value) shown when the additives are present further supports the inhibition of mild steel in $2 \mathrm{M} \mathrm{HCl}$ by the additive (Tabs. 1 and 2). The increase in half life indicates more protection of the metals by the additives [11].

The activation energy was calculated using the Arrhenius equation (2) below:

$$
\mathrm{Ea}=\left(2.303 \mathrm{RT} \mathrm{T}_{1} \mathrm{~T}_{2} \log \mathrm{k}_{1} / \mathrm{k}_{2}\right) / 1000\left(\mathrm{~T}_{2}-\mathrm{T}_{1}\right)
$$

where Ea= activation energy

$\mathrm{R}=$ is the gas constant in Joule $(\mathrm{J})$ $\mathrm{T}=$ Absolute temperature in Kelvin

$$
\mathrm{R}=8.314 \mathrm{Jmol}^{-1} \mathrm{~K}^{-1}
$$

$\mathrm{k}_{1}$ and $\mathrm{k}_{2}$ are rate constants at $\mathrm{T}_{1}$ $(303 \mathrm{~K})$ and $\mathrm{T}_{2}(313 \mathrm{~K})$ respectively or $\mathrm{T}_{1}^{1}$ $(313 \mathrm{~K})$ and $\mathrm{T}_{2}(323 \mathrm{~K})$.

The average activation energy for the dissolution of mild steel in $\mathrm{HCl}$ solution between $303 \mathrm{~K}$ and $313 \mathrm{~K}$ was found to be $20.15 \mathrm{KJmol}^{-1}[\mathrm{Tab} .1]$. In the presence of the additive, the corrosion rate decreased. This is evident in the increased value of activation energy $\left(\mathrm{Ea}=50.04 \mathrm{kJmol}^{-1}\right.$ for $\mathrm{HCl}$ - PXO system from 303 - 313K [Tab.2]. Two types of adsorption processes had been distinguished [12], physisorption in which the activation energy is less than about $40 \mathrm{KJmol}^{-1}$ and chemisorption where the activation energy is greater than 80 $\mathrm{KJmol}^{-1}$. On the basis of the experimentally determined activation energy values, the additive is physically adsorbed on the mild steel coupons. Therefore, it is probable that a multilayer protective coverage on the entire mild steel surface was obtained. 
The decrease in inhibition efficiency as temperature rises (Tab. 3) support the fact that the additive is physically adsorbed on the mild steel surface.

TABLE 3: The Inhibition efficiencies (\%) of Pyridoxol hydrochloride on mild steel corrosion in $2 \mathrm{M} \mathrm{HCl}$ at different temperatures.

\begin{tabular}{|c|c|c|c|}
\hline \multirow{2}{*}{$\begin{array}{l}\text { Inhibitor } \\
\text { C oncentr } \\
\text { a tion (M) }\end{array}$} & \multicolumn{3}{|c|}{ Inhib itor E ffic iency ( $\%$ ) } \\
\hline & $303 \mathrm{~K}$ & $313 \mathrm{~K}$ & $323 \mathrm{~K}$ \\
\hline${ }_{6}^{1.0} \times{ }^{\prime} \quad 10^{-}$ & 30.41 & 19.90 & 7.26 \\
\hline $\begin{array}{l}1.0 \times 10^{-} \\
5\end{array}$ & 44.49 & 20.33 & 12.82 \\
\hline $\begin{array}{l}1.0 \times 10^{-} \\
4\end{array}$ & 50.94 & 38.23 & 30.08 \\
\hline $\begin{array}{llll}1.0 & X & 10^{-}\end{array}$ & 61.34 & 43.83 & 40.01 \\
\hline $\begin{array}{l}1.0 \times 10^{-} \\
2\end{array}$ & 71.93 & 56.62 & 49.14 \\
\hline
\end{tabular}

Corrosion inhibition and Adsorption behaviour of pyridoxol hydrochloride on mild steel surface in $\mathrm{HCl}$ acid solution.

The inhibitive property of PXO may be explained by considering the adsorption of the PXO molecule through the heterocyclic nitrogen of the pyridine (fig. 8 ), available electron-rich oxygen and complex formation (surface chelation) on the corroding metal surface. These may be responsible for the formation of an oriented film layer, which essentially blocks discharge of $\mathrm{H}+$ and consequent dissolution of the metal ions.

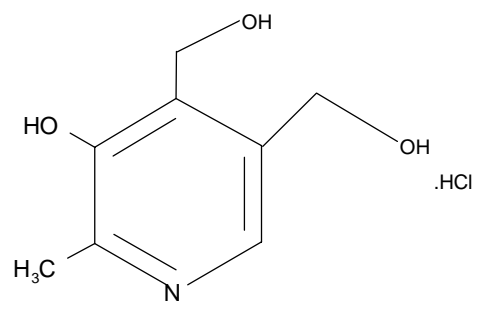

Pyridoxol Hydrochloride

Figure 8:- Pyridoxol hydrochloride.
The plot of C/e against C (M) where $\mathrm{C}$ represents inhibitor concentrations investigated $(1.0 \times 10-2 \mathrm{M}, 1.0 \times 10-3 \mathrm{M}$, $1.0 \times 10-4 \mathrm{M}, 1.0 \times 10-5 \mathrm{M}$ and $1.0 \times 10-$ $6 \mathrm{M}$ ) and $\mathrm{q}$ (which is defined as: $0.01 \mathrm{x}$ inhibition efficiency) represents surface area covered by the inhibitor that is linear (fig. 9) show that PXO conform to the Langmuir adsorption isotherm. The plot supports the assertion that the mechanism of corrosion inhibition is due to the formation and maintenance of a protective film on the metal surface and that the additive cover both the anodic and cathodic sites through uniform adsorption following Langmuir isotherm.

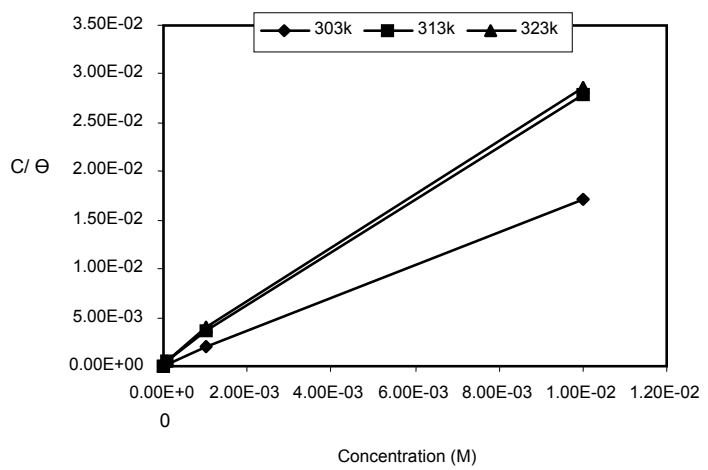

Figure 9: Langmuir adsorption isotherms plotted as $\mathrm{C} / \mathrm{e}$ versus $\mathrm{C}$ for inhibition of mild steel corrosion in $2 \mathrm{M} \mathrm{HCl}$ solution by Pyridoxal hydrochloride.

\section{Conclusion}

The compound, PXO inhibit the corrosion of mild steel in hydrochloric acid solution to an appreciable extent, particularly at decreased temperature and increased inhibitor concentration. Physical adsorption mechanism has been proposed for the inhibition action of the additive on the basis of the experimentally observed activation energy. The inhibitor action follows the Langmuir adsorption isotherm. The corrosion of mild steel in $\mathrm{HCl}$ in both inhibited and uninhibited reactions confirms a first order type of mechanism. This observation could go a along way in assisting corrosion scientists and engineers in solving corrosion problems. 
Received 28 June 2007

Accepted 16 July 2007

\section{References}

(1) K.R. Tretchewey, J. Chamberlain, Corrosion for Science and Engineering, $1^{\text {st }}$ edition, Longman, United Kingdom, 1995, 31 - 40.

(2) B. I. Ita, O. E. Offiong, Inhibition of mild steel corrosion in hydrochloric acid by 2 Ammopyridine and 2 - (Aminomethly) pyridine, Global J. Pure and Appl. Sci. 6, (1) (2000) 51 55.

(3) B. I. Ita, O. E. Offiong, The inhibition of mild steel corrosion in hydrochloric acid by 2, 2' pyridil and a - pyridoin, Mater. Chem. Phys. 51, (1997) $203-210$.

(4) O. K. Abiola, N. C. Oforka, E. E. Ebenso, A potential corrosion inhibition for acid corrosion of mild steel, Electrochemistry 20, (9) (2004) $409-413$.

(5) R.B. Rastoyi, M. M. Singh, K. Singh, M.Yadav, Organolic Dithiohydrazodicarbonamides as corrosion inhibitors for mild steel-dimethyl sulphoxide containing $\mathrm{HCl}$, Portugaliae Electrochimica Acta, 22, (2005) 315 - 332.

(6) A. O. James, N. C. Oforka, O. K. Abiola, Inhibition of corrosion of aluminium in hydrochloric acid by Pyridoxal hydrochloride, J. Corr. Sci. Eng. 7, Preprint 21, (2005) $1-10$.

(7) B. I. Ita, O. E. Offiong, Inhibition of steel corrosion in hydrochloric acid by pyridoxal, 4 methyl thiosemicarbazide, pyrdoxal - (4 methylthiosemicarbazone) and its $\mathrm{Zn}(11)$ complex, Mater. Chem. Phys. 48, (1997) 164 169.

(8) A. O. James, N. C. Oforka, O. K. Abiola, Inhibition aluminium 3SR corrosion in hydrochloric acid by Pyridoxal hydrochloride, Bulletin of electrochemistry, 22, (3) (2006) 111 116.

(9) A.I. Onuchukwu, The kinetic and mechanism of hydrogen evolution on corroding aluminium in alkaline medium, Mater. Chem.Phys. 25, (1998) 227 - 235.

(10) I. P. C. Okafor, E. E.Ebenso, U. J. Ekpe, Inhibition of the acid corrosion of aluminum by some derivatives of thiosemicarbazone, Bull. Chem. Soc. Ethiopia, 18, (12) (2004) 181 - 192. (11) B. I. Ita, A study of Corrosion inhibition of mild steel in $0.1 \mathrm{M}$ hydrochloric acid by $\mathrm{O}$ Vanillin and O-vanillin hydrazone, Bulletin of Electrochemistry, 20, (8) (2004) 363 - 370.

(12) K. O. Orubite, N. C. Oforka, Inhibition of the corrosion of mild steel in hydrochloric acid solutions by the extracts of leaves of Nypa fruiticans Wurmb, Mat. Let. 58, (2004) 1768 1772. 